História e Perspectivas, Uberlândia (57): 233-256, jul./dez. 2017

http://dx.doi.org/10.14393/HeP-v30n57-2017-9

\title{
DAS RAÍZES À FORMAÇÃO DA EDUCAÇÃO BRASILEIRA: OS SUBSÍDIOS DE PRIMITIVO MOACYR
}

Rosana Areal de Carvalho*

RESUMO: Primitivo Moacyr publicou seu primeiro livro em 1916, já trazendo a marca dos demais volumes que viriam vinte anos depois: a instrução como responsabilidade do Estado. Apresento elementos visando compreender a publicação dessa obra, entre os anos de 1936 e 1942, em meio a um complexo cenário político e cultural. Dentre as interpretações existentes para esse período, acato a de modernização do Estado brasileiro, com destaque para a criação do Ministério da Educação e Saúde (1931) e do Instituto Nacional de Pesquisas Pedagógicas (1937). Tomo de empréstimo os ensaios de Sérgio Buarque de Holanda (1936), Raízes do Brasil, e de Caio Prado Jr. (1942), Formação do Brasil Contemporâneo, como contraponto para a obra de Moacyr: das raízes da educação brasileira nos tempos imperiais à formação da escola nova nos anos 1930, discutindo o ofício desse historiador.

PALAVRAS-CHAVE: Instrução pública. Primitivo Moacyr. História da educação.

ABSTRACT: Primitivo Moacyr published his first book in 1916 already bringing the brand of other volumes that would come twenty years later: education as a state responsibility. In this paper I introduce elements aimed at understanding the publication of this work, between 1936 and 1942, amid a complex political and

* Doutorado em Ciências Humanas pela USP, professora associada na Universidade Federal de Ouro Preto, atuando na graduação e na pósgraduação, com História e Historiografia da Educação Brasileira. 
cultural scene. Among the existing interpretations of this period, I choose the modernization of the Brazilian state, highlighting the creation of the Ministry of Education and Health (1931) and the National Institute for Pedagogical Research (1937). I borrow the Sérgio Buarque de Holanda tests (1936), Raízes do Brasil, and Caio Prado Jr. (1942), Formação Contemporânea do Brasil, as a counterpoint to the work of Moacyr: the roots of Brazilian education in imperial times to formation of the new school in the 30 s, discussing the craft of this historian.

KEYWORDS: Public education. Primitivo Moacyr. The history of education.

Norteia este trabalho o objetivo de compreender a publicação da obra de Primitivo Moacyr, entre os anos de 1936 e 1942, no interior de um cenário de elevada complexidade política e cultural, como foram as décadas de 1930 e 1940 no Brasil. Em conformidade com tal complexidade, as leituras e os vieses explicativos sobre o período são variados, quando não, divergentes. Dentre as leituras possíveis, acato a que toma os anos 30 do século passado como um tempo no qual foram dados passos largos em prol da modernização do Estado brasileiro. Em razão do campo no qual se insere este trabalho, destaco a criação do Ministério da Educação e Saúde (1931) e do Instituto Nacional de Pesquisas Pedagógicas - INEP (1937).

Possivelmente como eco dessa mesma complexidade e o natural desejo de compreender a realidade, entre os anos 1920 e 1950 foram publicadas obras basilares sobre o Brasil, sob o estilo de ensaios, começando por Oliveira Viana e desaguando em Raymundo Faoro. Estes e outros brilhantes ensaístas foram reunidos sob o rótulo de "intérpretes do Brasil" por Santiago (2002): "Ao planejar esta antologia, julgamos que seria importante centrar a atenção dos leitores nos melhores ensaios escritos por brasileiros sobre o Brasil, depois da independência do país". 
Construí o título deste texto tomando de empréstimo os títulos dos ensaios de Sérgio Buarque de Holanda (1936), Raízes do Brasil, e de Caio Prado Jr. (1942), Formação do Brasil Contemporâneo, pois abarcam, em boa medida, o período cronológico das publicações de Moacyr - pois tratam da educação brasileira desde os tempos imperiais até as primeiras décadas republicanas -, da temática das raízes da educação nacional lançadas no período imperial e da sua formação, vislumbrada durante a primeira metade do século XX.

Para esse mesmo período, os interesses educacionais estavam voltados para os postulados escolanovistas ${ }^{1}$ que, ao contrário do que vinha ocorrendo na Europa, encontrou no Brasil educadores que buscaram aplicá-los nas escolas públicas. Não por acaso, dentre aqueles que assinaram o Manifesto dos Educadores da Escola Nova (1932), a maioria se alinhara às fileiras do Estado Novo (1937-1945). O próprio Manifesto foi escrito a partir de um convite do presidente Getúlio Vargas para que os educadores presentes à IV Conferência da Associação Brasileira de Educação apresentassem uma proposta para a educação nacional consoante ao governo "revolucionário instalado".

Neste exercício de análise e reflexão que ora compartilho, insere-se o propósito de explicitar alguns elementos passíveis de delinear a trama que configura o processo de modernização estatal, que passa pela reconfiguração das agências do Estado, tanto quanto pelos seus agentes e, por que não, pelo entendimento de que a missão dada ao sistema educacional era a de formar cidadãos para esse novo país. Ciente de que tal entendimento extrapola os marcos possíveis para este trabalho, porém movida pela instigante questão e pela possibilidade de aporte de algumas reflexões, inscrevo este debate também no campo da historiografia brasileira.

1 Refere-se aos educadores que assinaram o Manifesto dos Educadores da Escola Nova, em 1932. Dentre estes, se destacam Fernando de Azevedo, Anísio Teixeira, Lourenço Filho. 


\section{As raízes}

Primitivo Moacyr desembarcou no Rio de Janeiro ainda jovem, provavelmente nos primeiros anos republicanos. Não mais a corte, agora a capital republicana continuava exercendo uma forte atração sobre os jovens das províncias do Norte. Baiano de Salvador, Moacyr teve seus primeiros contatos com a instrução pública como professor de primeiras letras em Lençóis, no interior da Província da Bahia. Em seguida, transferindo-se para Recife, a convite do presidente da Província, trabalhou no Liceu de Recife. Para coroar esse percurso evolutivo, provavelmente instigado pelas experiências e pelo ambiente vivenciado no Liceu, seguiu para o Rio de Janeiro, onde alcançou a condição de bacharel em Direito. Os estudos desenvolvidos por Gondra e Marques (2011) identificaram sua atuação como advogado, por meio de anúncios publicados no Jornal do Commércio.

O início do século XX já o encontrou funcionário da Câmara de Deputados. Inteiramente dedicado aos registros dos debates parlamentares, dedicou-se com afinco ao trabalho que realizou durante trinta e três anos. Não tendo sido objeto de maiores trabalhos biográficos, são poucas as informações encontradas sobre a trajetória de Primitivo Moacyr. Se poucas na quantidade, são compensadas com os elogias, como o artigo de Francisco Venâncio Filho, publicado numa edição da Revista Cultura Política (1943), que reputa a Moacyr a iniciativa de publicação dos volumosos Documentos Parlamentares, cujo objetivo era dar publicidade aos debates dos mais variados temas ocorridos no plenário da casa legislativa.

Tal mérito pode ser confirmado por uma segunda iniciativa: a publicação, em 1916, do livro O ensino público no Congresso Nacional. Breve notícia. Para Carvalho e Mesquita,

ao expor tal documentação, Primitivo Moacyr produziu elementos para uma crítica contundente à produção legislativa brasileira, cuja inoperância aparece em cada projeto, independente da qualidade e acerto deste. Assim, é possível justificar e cultivar uma descrença quanto ao futuro educacional se este dependesse, apenas, das ações legislativas. (CARVALHO; MESQUITA, 2013, p. 52). 
Esse livro inaugura uma trajetória de dimensão inigualável que terá lugar entre os anos de 1936 e 1942 quando, já desfrutando da aposentadoria, Moacyr dedicou-se inteiramente à escrita educacional. Nesse curto espaço de seis anos, publicou quinze livros, tratando da educação brasileira no período imperial e republicano até os anos 1930, e mais dois trabalhos apresentados em congressos organizados pelo Instituto Histórico e Geográfico Brasileiro - IHGB.

Sobre o período imperial, Moacyr publicou seis volumes, todos na série Brasiliana, da Biblioteca Pedagógica Brasileira, sob a direção de Fernando de Azevedo, editados pela Companhia Editora Nacional. Nestes seis volumes, consta o enigmático subtítulo: subsídios para a história da educação brasileira. Enigmático, porque inspira muitas perguntas para as quais as hipóteses são fartas.

Fernando de Azevedo respondeu pelas bases sociológicas do movimento dos renovadores educacionais e esteve à frente de algumas reformas do ensino. Reputa-se a ele, também, a autoria do texto do Manifesto dos Pioneiros da Educação Nova, de 1932. Exímio observador da realidade brasileira, escreveu a introdução ao Censo de 1940 - A cultura brasileira, publicado em três volumes: no volume 1, Os fatores da cultura; no volume 2, A cultura; e, no volume 3, A transmissão da cultura. Este volume teve repercussão nacional e já alcançou inúmeras edições. Em estilo ensaístico, curiosamente não aparece em nenhuma das listas dos intérpretes do Brasil. Fixou sua base editorial na Companhia Editora Nacional, criando a Biblioteca Pedagógica Brasileira, em 1931. Nesta "Biblioteca" constavam cinco coleções, dentre as quais a Coleção Brasiliana, que ganhou maior destaque. Após a Revolução de 1930, fixou residência em São Paulo. Segundo Saviani, para Azevedo, "o ideal da Escola Nova envolvia três aspectos: escola única, escola do trabalho, escola-comunidade." (SAVIANI, 2007, p. 211).

O prefácio de Afrânio Peixoto, amigo e natural de Lençóis, Bahia, no primeiro volume de A instrução e o Império (1823-1853), vindo a público em 1936, dá algumas pistas e destaca uma virtude 
em Moacyr, referenciada também por Francisco Venâncio no artigo Primitivo Moacyr e a história da educação (1943). Afirma Peixoto que o autor, "modestamente", pensa que os seus livros contribuirão para "a futura história da educação brasileira", no que retruca o prefaciador, dizendo:

A futura história da educação brasileira, pensa o autor, modestamente, poderá agora ser feita... Ela já está aqui, neste livro, novo, original, prestante, e, às vezes, melancólico, sobre iniciativas, a sequência de nossas ideias, a descontinuidade de nossas ações... O Brasil é principalmente Brasil, em educação [...]. (PEIXOTO, 1936, p. 7).

Sobre a operação historiográfica, Afrânio afirma que "no Brasil não se pesquisa. (...) A história nessas condições é repetição, é comentado, é fantasia interpretativa." (PEIXOTO, 1936, p. 7).

Diferentemente, fez Moacyr que,

sobre educação nacional, investigou, nos arquivos, nas bibliotecas, nos livros, nos relatórios de governo e, de tudo, fez um livro objetivo, sem comentários, nem conclusões. Portanto, obra rara que vai produzir gerações de historiadores, que não o citarão... Que lhe importará? Que lhe importará mesmo o maldigam, depois de copiálo? (PEIXOTO, 1936, p. 7).

Uma carta de Anísio Teixeira abre o terceiro volume (1854-1889), abordando os diversos níveis de ensino. Nesta missiva ele acusa recebimento do segundo volume, que trata especialmente das reformas educacionais (1854-1888), tece algumas considerações e também elogia o trabalho de Primitivo Moacyr. Teixeira faz uma leitura dos esforços inócuos no campo da educação brasileira, caracterizado por "grandes planos gerais, com grandes debates de princípios, chocando ideais educativos", ao invés de "estudar os problemas concretos", de "analisar as necessidades reais e típicas", de forma a "examinar as dificuldades e facilidades características de execução, de realização" (TEIXEIRA, 1938, p. 11). 
Afirma que o trabalho de Moacyr "é um primeiro passo para o estudo intelectual da educação nacional. Com os seus volumes, estamos a sentir ao vivo como nunca faltaram ideias..." (TEIXEIRA, 1938, p. 11) Muito ao contrário, à abundância de ideias contrapunha a inoperância generalizada. Conclui, dizendo:

Se ao lado dos seus quatro volumes de história das ideias educacionais do Brasil, se fizer a história das realidades educativas do Brasil, talvez não se consiga senão um volumezinho mofino e franzino. Somos, assim esgalhados e frondosos em ideias, e pecos e estéreis, em frutos. O seu grande serviço está sendo o de nos mostrar isso e não apenas nos dizer isto. (TEIXEIRA, 1938, p. 11-12).

Anísio Teixeira, natural da Bahia, já havia se afastado da vida política, desgostoso com os rumos tomados desde 1935 e que vieram a desembocar no Estado Novo, quando escreveu a carta a Primitivo Moacyr. Foi um dos poucos pioneiros da Educação Nova que não se alinhou com o governo ditatorial de Vargas. Esteve à frente da Secretaria de Educação e Cultura do Distrito Federal até o final de 1935, quando se demitiu e passou a se dedicar a assuntos comerciais. Somente retornou ao Rio de Janeiro em 1951. Sua contribuição para a arquitetura do escolanovismo se deu nas bases filosóficas e políticas da renovação escolar.

Sobre o período republicano, dois volumes ainda foram publicados na mesma Coleção Brasiliana - A instrução pública no Estado de São Paulo, abrangendo a primeira década republicana. Os sete volumes de $A$ instrução e a República foram editados pela Imprensa Nacional, sob os auspícios do Instituto Nacional de Pesquisas Pedagógicas - INEP, à época dirigido por Lourenço Filho.

Deve-se a Lourenço Filho as bases psicológicas da Escola Nova. Em 1931, assumiu a chefia de gabinete do Ministério da Educação e Saúde e se instalou no Rio de Janeiro. Costume comum à época entre os intelectuais, tinha também sua base editorial, na Editora Melhoramentos. Dirigiu o INEP entre 1938 e 1946. 
Aqui se completa a rede que colocou Moacyr próximo da "trindade cardinalícia" (SAVIANI, 2007, p. 217), porta-voz do movimento escolanovista no Brasil: Fernando de Azevedo, Anísio Teixeira e Lourenço Filho. Cumpre destacar que Afrânio Peixoto, amigo e conterrâneo, prefaciador do primeiro volume de 1936, também foi um dos signatários do Manifesto dos Educadores da Educação Nova (1932).

Segundo Venâncio Filho (1943), a publicação pela Imprensa Nacional respondia à compreensão de Moacyr de que, afinal, seus livros não representavam tanto interesse econômico. Há outras hipóteses, como a que indica terem sido, esses volumes, resultados da época em que colaborou como pesquisador no INEP. Nesse trabalho, o autor dá especial atenção para as reformas educacionais, tema central de cinco dos sete volumes. As fontes que permitiram tamanha produtividade foram os documentos do Estado, tanto da esfera legislativa quanto executiva. Para Saviani (2004, p. 4), o termo fonte, em português, aponta para dois significados.

Por um lado, significa o ponto de origem, o lugar de onde brota algo que se projeta e se desenvolve indefinidamente e inesgotavelmente. Por outro lado, indica a base, o ponto de apoio, o repositório dos elementos que definem os fenômenos cujas características se busca compreender. (SAVIANI, 2004, p. 4).

Não escapa, portanto, nesse conceito, a ideia de nascente, de manancial. Entretanto, as fontes históricas são produções humanas e, enquanto tal, apontam para a inesgotabilidade. Porém, elas não são a origem do fenômeno histórico: "As fontes estão na origem, constituem o ponto de partida, a base, o ponto de apoio da construção historiográfica que é a reconstrução, no plano do conhecimento, do objeto histórico estudado." (SAVIANI, 2004, p. 5). O autor observa ainda que os documentos, os vestígios, indícios e toda a miríade de objetos produzidos pelo homem não são fontes em si mesmos, mas se constituem enquanto tal pela operação historiográfica, movida por uma questão, um problema. 
Sendo assim, os documentos selecionados por Moacyr tornam-se fontes, subsídios para a história da educação. Então, as perguntas que não calam: qual teria sido o leit motiv de Primitivo Moacyr? Por que escolheu a educação? O motivo era dar visibilidade às ações parlamentares? Era um republicano? Apoiou o movimento da Escola Nova?

À primeira vista, a concepção de história de Primitivo Moacyr se aproxima muito de um historicismo atrelado a uma concepção de verdade, ou a uma história oficial, perfilada nos artigos que compõem a legislação educacional e nos resultados, justificativas e propósitos componentes dos relatórios produzidos pela esfera executiva. Desta forma, afasta-se do modelo preconizado pelos grandes ensaístas contemporâneos. Porém, não raro encontramos a presença do autor, seja no estilo levemente irônico, seja lançando mão de recursos gráficos como o itálico e, não raro, as reticências, reservando ao leitor a conclusão. Mas sempre de forma discreta. Isso para não dizer que está presente na própria escolha dos temas, nos recortes, naquilo que explicita e também no que não dá voz.

No seu primeiro livro - O ensino público no Congresso Nacional. Breve Notícia, publicado em 1916, por exemplo, inicia e finaliza com o tema da "desoficialização" do ensino, tomando a posição de homem de estado, bem como daquele que compreende o ensino como responsabilidade governamental. São traços assim que permitem a autores como Cardoso afirmarem a preferência que Moacyr dá ao ensino primário em detrimento do ensino superior.

Em relação ao ensino primário, a educação fundamental, Primitivo Moacyr deixa claro ao longo de toda a sua obra, que o considerava o mais importante nível de ensino e aquele ao qual o poder público deveria dedicar maior atenção. Muitas vezes lamentou a pouca atenção que os diferentes governos, tanto do Império quanto da República, dispensaram ao ensino primário. (CARDOSO, 2002, p. 918). 
Para construir sua obra, Primitivo Moacyr lançou mão de copiosa documentação oficial, dentre documentos parlamentares, legislações, relatórios de presidentes de províncias, de diretores da instrução pública e outros sujeitos envolvidos no cenário educacional, particularmente no campo da administração escolar em seus diversos níveis. Como homem de estado, Primitivo Moacyr, em O ensino público no Congresso Nacional. Breve notícia (1916), exaltou as ações do regime republicano para "as cousas do ensino publico", afirmando que "a sua operosidade tem sido copiosa" (MOACYR, 1916, p. 5). Porém, isso não o impediu de expor os acalorados e, por vezes, inúteis debates sobre o arquivamento ou a inexequibilidade de inúmeras legislações. Assim, buscou dar visibilidade às iniciativas do Estado em prol da instrução pública e procurou evidenciar as tensões presentes no campo, usando-as como subsídio para compreender o estágio educacional em que se encontrava a nação brasileira: pré-requisito fundamental para o avanço cultural, ou seja, o movimento de renovação educacional.

Não desconsidero o discurso valorativo implícito na denominação "Estado Novo", período no qual se insere o recorte da análise aqui proposta. Tal denominação encerra um jogo de forças, "um ato de poder, como os historiadores sabem por dever de ofício", como afirmam Gomes e Abreu (2009, p. 1). Porém, tenho como hipótese que a publicação dos quinze volumes de Primitivo Moacyr se inscreve nesse "ambicioso projeto político-cultural", conforme as mesmas autoras anunciam, que cercou as ações governamentais (GOMES; ABREU, 2009, p. 2).

O Estado Novo e seus ideólogos conseguiram trazer para si todos os méritos da criação de um país de todos, unificado política e culturalmente, através da construção de um povo mestiço, em termos festivos e musicais, tanto no samba e no carnaval, como em diversas manifestações folclóricas de todas as partes do país. O governo Vargas e a década de 1930 passaram a representar, na memória nacional, um momento de ruptura do passado cultural brasileiro. A valorização da música popular, do carnaval e até mesmo da capoeira - tudo nos faz crer - precisava esperar esses novos tempos. (GOMES; ABREU, 2009, p. 9). 
Consoante a esse projeto, é notório o movimento de âmbito nacional em defesa da escola pública a partir dos anos de 1930. E não se trata de mera coincidência a concomitância com o desenvolvimento capitalista, articulando urbanização e industrialização. A ampliação da estrutura produtiva implicava em exigências no nível da superestrutura, dentre elas a correspondência no campo educacional. Enfim, de quem era a responsabilidade pela educação? Para Moacyr, esta responsabilidade compete ao Estado, e o governo Vargas não se negou a exercer essa função. Sanfelice observa "[...] um Estado cada vez mais educador do povo" (SANFELICE, 2007, p. 544), a começar pela Reforma Francisco Campos, passando pelas Leis Orgânicas dos anos 1940, a Constituição de 1946, até desaguar na LDB de 1961.

Por outro lado, que sujeitos estariam indicados para receber essa educação? Quem, em nome do Estado, determinaria o tipo e o grau de educação indicado para esta ou aquela população?

Para Sanfelice,

Os interlocutores essenciais da discussão, no âmbito das elites econômicas ou culturais, representavam basicamente o velho e o novo. O velho Brasil pré-1930 tinha como sua expressão maior, em questões educacionais, a Igreja Católica. O novo, emergente a duras penas no interior do velho, se fazia representar, grosso modo, por intelectuais identificados genericamente como liberais e outros homens da administração pública. (SANFELICE, 2007, p. 543).

\section{A formação}

A partir dos anos 1930, é possível verificar um intenso movimento em prol da educação pública no Brasil, decorrente de inúmeras ações que tiveram lugar na década anterior, como as reformas educacionais promovidas por educadores vinculados ao movimento escolanovista, a criação da Associação Brasileira de Educação-ABE, em 1924, e as conferências por ela promovidas. 
O processo de urbanização e industrialização em voga, respondendo pelo desenvolvimento capitalista, também contribuiu para a atividade educacional, duplamente. Por um lado, ao estabelecer novos interesses a serem alcançados pela escola no campo da formação; por outro lado, ao acelerar o processo migratório, trazendo para as cidades uma população que, visando o ingresso no mercado de trabalho em expansão, aumentava a demanda pela escola pública.

Visto por esse ângulo, é perfeitamente compreensível a criação do Ministério da Educação e Saúde (Decreto n. 19.444, 1930), dirigido por Francisco Campos, até 1932, e por Gustavo Capanema, de 1934 a 1945, quando finda o Estado Novo. O conjunto de reformas encabeçado por Francisco Campos demonstra a disposição do governo Vargas em tratar a educação como questão nacional. Também nessas reformas, um inusitado: o ensino religioso retorna, por meio de decreto, à escola pública, desencadeando uma tensão, que se avoluma nos anos seguintes, entre os católicos, tido como conservadores, e os escolanovistas, ou renovadores. Até então, compondo a Associação Brasileira da Educação - $A B E$, os primeiros se afastam e constituem a Confederação Católica Brasileira de Educação, em 1933.

Tratar a educação como uma questão nacional implicava em medidas comuns a todo o território nacional. Otaíza Romanelli afirma que

Efetivamente, credita-se-lhe, entre outros méritos, o de haver dado uma estrutura orgânica ao ensino secundário, comercial e superior. Era a primeira vez que uma reforma atingia profundamente a estrutura do ensino e, o que é importante, era pela primeira vez imposta a todo o território nacional. Era, pois, o início de uma ação mais objetiva do Estado em relação à educação. (ROMANELLI, 2007, p. 131).

No entanto, como a própria autora destaca, as necessidades do desenvolvimento capitalista não foram atendidas pela escola, mesmo considerando uma excepcional expansão desta. Talvez, 
um dos motivos esteja, justamente, no conjunto de reformas de Francisco Campos, que priorizou o ensino secundário e o ensino superior, ficando o ensino primário às expensas dos governos estaduais.

A Constituição de 1934 deu continuidade ao federalismo delineado pela Constituição de 1891, somado a alguns aspectos inovadores, como "reflexo das mudanças ocorridas no país" (FAUSTO, 1996, p. 351). Sobre a ordem econômica e social, sobre a família e sobre a educação e a cultura versaram títulos inexistentes nas constituições anteriores, no rol da ampliação dos direitos civis e sociais. Estabelecia o princípio do ensino primário gratuito e da frequência obrigatória, sendo facultativo o ensino religioso, aberto a todos os credos.

Para Cury (2005), somente na Constituição de 1988 teremos "um capítulo tão completo" sobre a educação, vista então como "um direito social próprio da cidadania."

Foram muitos os compromissos assumidos constitucionalmente e, se nem todos foram efetivados, não estavam desprovidos de valor:

E esses compromissos serão bandeiras de lutas em prol de uma educação pública de qualidade mesmo quando o autoritarismo ditatorial impôs sua marca explícita na sociedade brasileira. É o caso de 1937 com o golpe do Estado implantando a ditadura do Estado Novo. (CURY, 2005, p. 23).

A luta por uma educação pública de qualidade foi interrompida durante o Estado Novo diante da censura política recorrente. A Constituição de 1937, nas suas "Disposições finais e transitórias", concedia ao presidente o poder de governar por meio de decretosleis, suspendia as liberdades civis e autorizava o governo a aposentar funcionários civis e militares por interesse do serviço público ou mera conveniência do regime.

Para Cury, ocorre um retrocesso quanto ao papel do Estado, colocando este como "subsidiário da família e do segmento privado na oferta da educação escolar" (CURY, 2005, p. 23). 
Venceram os conservadores católicos!? A exclamação e a interrogação emparelham-se com a complexidade do cenário político do Estado Novo. Complexidade porque a convivência entre posições políticas diversas permanece; forças antagônicas continuam presentes em postos chaves do governo.

Segundo Velloso, a contradição e o antagonismo estavam na raiz do projeto educativo do Estado novo, presentes, em especial, no Ministério da Educação, dirigido por Gustavo Capanema, e no Departamento de Imprensa e Propaganda - DIP, sob a batuta de Lourival Fontes.

Entre estas entidades ocorreria uma espécie de divisão do trabalho: o ministério Capanema voltava-se para a formação de uma cultura erudita, preocupando-se com a educação formal; enquanto que o DIP buscava, através do controle das comunicações, orientar as manifestações da cultura popular. (VELLOSO, 1987, p. 4).

Em torno do ministro Capanema reunia-se um grupo de intelectuais ligados à vanguarda do movimento modernista, como Carlos Drummond de Andrade, Lúcio Costa, Oscar Niemeyer, Mário de Andrade, Portinari. Na composição do DIP, outro grupo, composto por Cassiano Ricardo, Menotti Del Picchia e Cândido Motta Filho, intelectuais caracterizados por um pensamento centralista e autoritário, contribuindo para o rígido controle dos meios de comunicação. Em comum, estabeleciam uma íntima relação entre propaganda política e educação: "Apresentandose como o grupo mais esclarecido da sociedade, os intelectuais buscam 'educar' a coletividade de acordo com os ideais doutrinários do regime." (VELLOSO, 1987, p. 4).

Desde 1834, convivia-se com a descentralização da oferta dos serviços educacionais no Brasil nos níveis elementar e secundário, tornando supérflua a existência de um órgão nacional que tratasse das questões gerais do ensino. Entretanto, nos primeiros anos da República, não foram poucas as vozes que se manifestaram contrárias a essa situação, clamando por uma solução de continuidade que só seria possível com a presença 
mais firme do Estado brasileiro. Moacyr apresenta muitas dessas vozes no trabalho de 1916.

Antes mesmo de 1889, Rui Barbosa já apresentava tal propositura. Segundo Lourenço Filho: "Não desejava ele apenas um órgão colegiado, mas outro também que servisse à documentação e à difusão de novas ideias sobre o ensino, com investigação de seus problemas na vida nacional." (LOURENÇO FILHO, 2005, p. 180). Respondia a essas mesmas necessidades, ou seja, ampliar o conhecimento e a compreensão do percurso educacional brasileiro, a criação da Diretoria Geral de Estatística (DGE), cuja tarefa, "quase impossível", era produzir os censos decenais e as estatísticas da instrução (GIL, 2009).

Podemos observar, entretanto, que a ideia de um órgão central, ou, numa outra dimensão, um centro de estudos, esteve implícita em muitos eventos, como a Exposição Pedagógica, de 1883; a formação de organismos, como a Sociedade Promotora de Instrução ou mesmo a Associação Brasileira de Educação, de 1923, que promoveu várias conferências nacionais nas primeiras décadas do século XX. Assim foi a criação do Pedagogium: "um órgão propulsor de reformas e melhoramentos de que carecesse a educação nacional." (LOURENÇO FILHO, 2005, p. 181).

Em meados dos anos 1930, em sintonia com a criação do Ministério de Educação e Saúde, o então ministro Gustavo Capanema preparou um projeto que deu origem à Lei n. 378, de 13 de janeiro de 1937, criando o Instituto Nacional de Pedagogia, com a missão de "realizar pesquisas sobre os problemas do ensino nos seus diferentes aspectos". Em 1938, o Decreto Lei n. 580, de 30 de julho, alterou o nome do órgão para Instituto Nacional de Estudos Pedagógicos. No mesmo período, comemorava-se o centenário do IHGB.

Lourenço Filho rememora o projeto de Capanema com o excerto da exposição de motivos:

Não possui, ainda, o nosso país um aparelho central destinado a inquéritos, estudos, pesquisas e demonstrações, sobre os problemas do ensino, nos seus diferentes aspectos. É evidente a 
falta de um órgão dessa natureza, destinado a realizar trabalhos originais nos vários setores do problema educacional, e, ao mesmo tempo, a recolher, sistematizar e divulgar os trabalhos realizados pelas instituições pedagógicas, públicas e particulares. Além disso, incumbir-se-á de promover o mais intenso intercâmbio no terreno das investigações relativas à educação, com as demais nações em que este problema esteja sendo objeto de particular cuidado de parte dos poderes públicos ou das entidades privadas. (LOURENÇO FILHO, 2005, p. 181).

Uma das funções do instituto era "organizar a documentação relativa à história e ao estado atual das doutrinas e técnicas pedagógicas". Entretanto, não havendo técnicos suficientes para cuidar dos assuntos propriamente pedagógicos, foi necessário "ocupar pesquisadores externos". A documentação que o INEP começou a recolher abrangia dados estatísticos e um "ementário geral da legislação sobre o ensino e educação, a partir dos primeiros atos do Reino Unido". E acrescenta:

O aspecto propriamente histórico encontrou um colaborador espontâneo na figura do inesquecível pesquisador Primitivo Moacyr, auxiliado, com rara dedicação, pelo Dr. Rui Guimarães de Almeida, também infelizmente já desaparecido. A ambos se deve a publicação da obra A Instrução e a República, em sete volumes, que o Inep editou nos anos de 1941 e 1942. (LOURENÇO FILHO, 2005, p. 183).

Portanto, de acordo com Lourenço Filho, Moacyr foi um prestimoso colaborador do INEP, o que lhe teria valido, então, a publicação dos sete volumes de $A$ instrução e a República pela Imprensa Oficial. Quanto à coautoria, não disponho de outra fonte que confirme esta informação. Por outro lado, é importante mencionar que, simultaneamente à publicação pela Imprensa Oficial, outros livros de Moacyr continuavam sendo publicados pela Companhia Editora Nacional. 


\section{Os subsídios}

Andréa Dantas, em sua tese de doutorado, ao tratar do projeto editorial do INEP, discorre sobre o formato e o conteúdo do boletim mensal, publicado com o título de Subsídios para a história da educação brasileira, cujo objetivo era divulgar a legislação federal da educação e informações gerais sobre o desenvolvimento da educação no país e no estrangeiro, ampliada com a inclusão das legislações estaduais (DANTAS, 2001, p. 128). Esse boletim foi publicado de 1940 a 1944, sendo substituído pela Revista Brasileira de Estudos Pedagógicos.

Até 1940, Moacyr havia publicado seis volumes pela Companhia Editora Nacional e neles constava exatamente como subtítulo subsídios para a história da educação no Brasil. A que se deve tal coincidência? Pelos relatos de Lourenço Filho, por essa época, Moacyr já era um pesquisador colaborador do INEP. Teria sido dele a sugestão? Pelas descrições que Dantas faz sobre o boletim, outras semelhanças e coincidências com os livros de Moacyr podem ser identificados. Para a autora, a justificativa para a criação dos "Subsídios", ou seja, dos boletins, apoiava-se

na intenção de criar uma memória educacional do país centrada no arrolamento de atos legais. A organização da memória legislativa informa o leitor muito mais sobre as providências administrativas tomadas pelo poder público, no âmbito federal e estadual, do que o registro de ocorrências restritas ao campo pedagógico. (DANTAS. 2001, p. 131).

Ou seja, a forma de entender e apresentar a educação brasileira numa linha evolutiva é semelhante aos livros organizados por Primitivo Moacyr, tanto aqueles publicados pela Imprensa Oficial, sob a tutela do INEP, como os volumes publicados na Coleção Brasiliana, da Companhia Editora Nacional. No Boletim n. 17, de 1942, Lourenço Filho relata "o esforço para coligir toda a documentação referente à educação nos períodos anteriores à República, além do preparo para a utilização destas informações". E continua dizendo da participação de Moacyr no INEP: 
com a desinteressada colaboração do Dr. Primitivo Moacyr, a quem já se deviam excelentes estudos sobre o ensino no império, vêm este Instituto ultimamente publicando a obra "a Instrução e a República”, de que já se tiraram quatro volumes, e que se tirarão mais três (LOURENÇO FILHO, 1942 apud DANTAS, 2001, p. 131).

Para Dantas, Moacyr "não foi chamado para publicar uma obra que já estava finalizada e que era de interesse do Instituto divulgar". O convite adveio de sua excelência na sistematização de dados, pois o INEP possuía esses dados e era necessária sua organização e ordenação. Reconhece que "a forma como os registros presentes no boletim mensal 'Subsídios para a História da Educação Brasileira' do Inep guardam muito do modo como Primitivo Moacyr organiza os dados referentes às províncias" (DANTAS, 2001); além da concomitância de nomenclatura, focada nos subsídios.

Acrescenta, então, que tais "ocorrências educacionais" a remete à hipótese de que, "ao dispor no boletim mensal do Instituto as informações oriundas dos estados do mesmo modo como estas são apontadas nas publicações organizadas por Primitivo Moacyr, Lourenço Filho está referendando o formato com que o primeiro produz história da educação". (DANTAS, 2001, p. 133).

Francisco Venâncio Filho, em 1943, após a morte de Moacyr, publicou na revista Cultura Política um pequeno, mas elogioso artigo sobre o pesquisador. Sobre a publicação de seus livros, no que tange à coleção $A$ instrução e a República, comenta:

Escrupuloso, Primitivo Moacyr não quis continuar aí [Companhia Editora Nacional] sua obra, por certo de reduzido interesse econômico. Encontra na clarividência de educador do professor Lourenço Filho o oferecimento oficial do Instituto Nacional de Estudos Pedagógicos, que logo inicia a publicação do período republicano. (VENÂNCIO FILHO, 1943, p. 96).

Os três primeiros volumes de A instrução e a República foram publicados em 1941, tratando, respectivamente, da Reforma 
Benjamin Constant, dos códigos Fernando Lobo e Epitácio Pessoa, nos primeiros anos republicanos, cobrindo o período de 1890 a 1916. Considerando o interregno normal entre a entrega de originais e a impressão, e que o período coberto pelos três volumes coincide com o livro de 1916, parece-me que a tese de Dantas não procede. Ou seja, Moacyr teria sido convidado pela trajetória editorial que perseguia.

Porém, não resta dúvida que sua colaboração no INEP veio contribuir, em sumo grau, para as posteriores publicações, muito especialmente aos dois volumes sobre a instrução pública em São Paulo, na primeira década da República. Segundo Venâncio Filho:

Graças à alta compreensão que tiveram, desde logo, o secretário de Educação de Minas Gerais, Cristiano Machado, e seu digno auxiliar João Gomes Teixeira, pôde Primitivo Moacyr deixar concluídos os originais relativos a esse Estado. Preso sempre ao documento, só desejava reunir o que fosse projeto, leis, regulamentos e programas, base para as análises posteriores. (VENÂNCIO FILHO, 1943, p. 97).

Como pesquisador do INEP, Moacyr teve as portas abertas aos acervos documentais estaduais e, provavelmente, os originais sobre Minas Gerais ficaram nos arquivos do INEP. Como assinala Venâncio Filho, o interesse do pesquisador era reunir as fontes documentais para análise futura: eram os subsídios para a história da educação no Brasil.

Inscrita numa historiografia bem próxima da corrente valorizada pelo Instituto Histórico e Geográfico Brasileiro e apadrinhada por instituições como a Companhia Editora Nacional e o INEP, entendemos a produção de Primitivo Moacyr inserida numa chave que estimula o conhecimento como requisito para o desenvolvimento, ou seja, a ciência a serviço do progresso.

Nesse sentido, considerando os contatos de diferentes intensidades com os componentes da "trindade cardinalícia" da Escola Nova no Brasil, não é demais entender Moacyr como portavoz dos escolanovistas, signatários do Manifesto dos Pioneiros da Educação Nova (1932), os quais, dentre outros pleitos, 
defenderam no manifesto o "preparo intensivo das forças culturais e o desenvolvimento das aptidões à invenção e à iniciativa" como "fatores fundamentais do acréscimo de riqueza de uma sociedade". Criticavam o "empirismo grosseiro" característico das ações educativas do estado brasileiro até então, enaltecendo "o tratamento científico dos problemas da administração escolar". Empirismo este que Moacyr não se cansou de exemplificar em suas obras, que Anísio Teixeira tão bem resumiu - fartos em ideias e pecos em realização - e a respeito do qual o próprio Afrânio Peixoto também se expressou: "O Brasil é principalmente Brasil, em educação” (PEIXOTO, 1936, p. 7-8).

Assim, compreendo que a produção bibliográfica de Primitivo Moacyr não foi fortuita, ao contrário, acusa intencionalidade. Para tanto, contribuíram, e muito, as sociabilidades possibilitadas pelo trabalho desenvolvido na Câmara dos Deputados e a familiarização com a documentação parlamentar e do Estado, bem como o interesse pelos assuntos educacionais posto a público com o livro de 1916 - O ensino público no Congresso Nacional: Breve notícia -, que o aproximou, dentre outros motivos, de intelectuais e educadores do calibre de Afrânio Peixoto, Lourenço Filho e Anísio Teixeira.

Respondeu a um propósito, a um convite - mesmo que não formulado oficialmente -, estimulado por aqueles com os quais convivia, pelo ambiente que frequentava, pela percepção do interesse que poderia suscitar a divulgação de uma coletânea de documentos organizados, sistematizados, sobre o que já se havia produzido sobre a história da educação. Daí, a confiança expressa no subtítulo dos livros - "subsídios para a história da educação no Brasil” - ou mesmo pela saudação de Afrânio Peixoto no primeiro volume publicado. Não por acaso, o modelo criado por Primitivo Moacyr, de apresentar a legislação brasileira como subsídio para a história da educação no Brasil, foi tomada por Lourenço Filho como exemplo para a memória educacional. Primitivo Moacyr não pretendeu fazer uma "interpretação" do Brasil. Não foi um ensaísta. Porém, não só estava atualizado com a concepção historiográfica predominante em sua época - a 
história documental -, como também foi um precursor no campo da história da educação brasileira, ao dar visibilidade à profusa e inoperante legislação educacional.

\section{Fontes consultadas}

Documentos

MANIFESTO dos Pioneiros da Educação Nova, 1932.

Obras de Primitivo Moacyr

MOACYR, Primitivo. O ensino público no Congresso Nacional: breve noticia. Rio de Janeiro: s/ed, 1916

. A instrução e o Império: subsídios para a história da educação no Brasil. 1823-1853. São Paulo: Companhia Editora Nacional, 1936. v. I. Série 5., Brasiliana, v. 66, Biblioteca Pedagógica Brasileira.

A instrução e o Império: reforma do ensino: 1854-1888. São Paulo: Companhia Editora Nacional, 1937. v. II. (Série 5., Brasiliana, v. 87, Biblioteca Pedagógica Brasileira).

. A instrução e o Império: 1854-1889. São Paulo: Companhia Editora Nacional, 1938. v. III. (Série 5., Brasiliana, v. 121, Biblioteca Pedagógica Brasileira).

A instrução e as províncias: subsídios para a história da educação no Brasil: 1834-1889: das Amazonas ás Alagoas. São Paulo: Companhia Editora Nacional, 1939. v. I. (Série 5., Brasiliana, v. 147, Biblioteca Pedagógica Brasileira).

A instrução e as províncias: subsídios para a história da educação no Brasil: Sergipe, Bahia, Rio de Janeiro, São Paulo e Mato Grosso. São Paulo: Companhia Editora Nacional, 1939. v. II. (Série 5., Brasiliana, v. 147A, Biblioteca Pedagógica Brasileira). 
MOACYR, Primitivo. A instrução e as províncias: subsídios para a história da educação no Brasil: Espírito Santo, Minas Gerais, Paraná, Santa Catarina e Rio Grande do Sul. São Paulo: Companhia Editora Nacional, 1940. v. III. (Série 5., Brasiliana, v. 147B, Biblioteca Pedagógica Brasileira).

A instrução pública no estado de São Paulo: a primeira década republicana: 1889-1893. São Paulo: Companhia Editora Nacional, 1942. v. I. (Série 5., Brasiliana, v. 213, Biblioteca Pedagógica Brasileira).

. A instrução pública no estado de São Paulo: 1889-1900. São Paulo: Companhia Editora Nacional, 1942. v. II. (Série 5., Brasiliana, v. 213A, Biblioteca Pedagógica Brasileira).

. A instrução e a República, I: Reforma Benjamin Constant: 1890-1892. Rio de Janeiro: Imprensa Oficial, 1941.

. A instrução e a República, II: Código Fernando Lobo: 18921899. Rio de Janeiro: Imprensa Oficial, 1941.

. A instrução e a República, Ill: Código Epitácio Pessoa: 19001916. Rio de Janeiro: Imprensa Oficial, 1941.

A instrução e a República, IV: Reformas Rivadávia e C. Maximiliano. Rio de Janeiro: Imprensa Oficial, 1942.

. A instrução e a República, V: Reforma João Luís Alves-Rocha Vaz. Rio de Janeiro: Imprensa Oficial, 1944.

. A instrução e a República, VI: Ensino Técnico Industrial: 18921928. Rio de Janeiro: Imprensa Oficial, 1942.

. A Instrução e a República, VII: Ensino Agronômico: 1892-1929. Rio de Janeiro: Imprensa Oficial, 1942.

\section{Referências bibliográficas}

BOTELHO, André. Passado e futuro nas interpretações do país. Tempo Social, São Paulo, v. 22, n. 1, p. 47-66, 2010.

CARDOSO, Tereza Molo R. F. Levy. Primitivo Moacyr. In: FÁVERO, M. de Lourdes de A.; BRITTO, Jader de M. (Orgs.). Dicionário dos educadores no Brasil. Rio de Janeiro: Ed. UFRJ; Brasília: INEP, 2002. p. 916-920. 
CARVALHO, Rosana Areal; MESQUITA, Ilka Miglio. O ensino público no Congresso Nacional. Breve notícia de Primitivo Moacyr. In:

Clássicos da educação brasileira. Belo Horizonte: Mazza, 2013. v. III.

CURY, Carlos Roberto Jamil. A educação nas constituições brasileiras. In: STEPHANOU, Maria; BASTOS, Maria Helena Câmara. Histórias e memórias da educação no Brasil. Petrópolis: Vozes, 2005. v. III, p.17-28.

DANTAS, Andréa Maria Lopes. A urdidura da Revista Brasileira de Estudos Pedagógicos nos bastidores do Instituto Nacional de Estudos Pedagógicos: a gestão Lourenço Filho (1938-1946). Tese (Doutorado em História e Filosofia da Educação) - Programa de Estudos Pós-Graduados em História e Filosofia da Educação. Pontifícia Universidade Católica de São Paulo, São Paulo, 2001.

FAUSTO, Boris. História do Brasil. 4. ed. São Paulo: EDUSP, 1996.

GIL, Natália de Lacerda. A produção dos números escolares (1871-1931): contribuições para uma abordagem crítica das fontes estatísticas em História da Educação. Revista Brasileira de História. São Paulo, v. 29, n. 58, p. 341-358, 2009.

GOMES, Angela de Castro; ABREU, Martha. A nova "Velha" República: um pouco de história e historiografia. Tempo, Niterói, v. 13, n. 26 , p. 1-14, 2009.

LOURENÇO FILHO, Manoel Bergstron. Antecedentes e primeiros tempos do INEP. Revista Brasileira Estudos Pedagógicos, Brasília, v. 86 , n. 212, p.179-185, jan./abr, 2005. Publicado originalmente na RBEP v. 42, n. 95 , p. 8-17, jul./set. 1964.

NAGLE, Jorge. Educação e sociedade na Primeira República. São Paulo: EPU; Rio de Janeiro: Fename, 1974.

NAGLE, Jorge. A educação na primeira república. In: FAUSTO, Boris (Org.). O Brasil Republicano: sociedade e instituições: 1889-1930. 2. ed. Rio de Janeiro; São Paulo: Difel, 1978. p. 259-291. Col. História Geral da Civilização Brasileira, Tomo III, 2. volume.

PEIXOTO, Afrânio. Prefácio. In: MOACYR, Primitivo. A instrução e o Império: subsídios para a história da educação no Brasil: 1823-1853. São Paulo: Companhia Editora Nacional, 1936. v. I. 
RICUPERO, Bernardo (Org.). Sete lições sobre as interpretações do Brasil. São Paulo: Alameda, 2007.

ROMANELLI, Otaíza de Oliveira. História da educação no Brasil: 19301973. 32. ed. Petrópolis: Vozes, 2007.

SANFELICE, José Luís. O Manifesto dos Educadores (1959) à luz da história. Educação e Sociedade, Campinas, v. 28, n. 99, p. 542-557, maio/ago. 2007.

SANTIAGO, Silviano (Coord.). Intérpretes do Brasil. 2. ed. Rio de Janeiro: Nova Aguilar, 2002. 3 v.

SAVIANI, Dermeval. Breves considerações sobre fontes para a história da educação. In: LOMBARDI, José Claudinei; NASCIMENTO, Maria Izabel Moura. Fontes, história e historiografia da educação. Campinas: Autores Associados; HISTEDBR; Curitiba: PUCPR; Palmas, PR: UNICS; Ponta Grossa: UEPG, 2004. (Coleção Memória da Educação).

SAVIANI Dermeval. História das ideias pedagógicas no Brasil. Campinas: Autores Associados, 2007.

TEIXEIRA, Anísio. Prefácio. In: MOACYR, Primitivo. A instrução e o Império: 1854-1889. São Paulo: Companhia Editora Nacional, 1938. v. III, p.11-12.

VELLOSO, Mônica Pimenta. Os intelectuais e a política cultural do Estado Novo. Rio de Janeiro: Centro de Pesquisa e Documentação de História Contemporânea no Brasil, 1987.

VENÂNCIO FILHO, Francisco. Primitivo Moacyr e a história da educação. Cultura Política, Rio de Janeiro, n. 24, p.94-97, 1943.

Recebido em maio de 2015. Aprovado em fevereiro de 2017. 